\title{
Electron-rich carbon nanorings as macrocyclic hosts for fullerenes.
}

\section{$\operatorname{AUTHOR}(\mathrm{S}):$}

Miki, Koji; Matsushita, Tsuyoshi; Inoue, Yuki; Senda, Yoshinori; Kowada, Toshiyuki; Ohe, Kouichi

\section{CITATION:}

Miki, Koji ...[et al]. Electron-rich carbon nanorings as macrocyclic hosts for fullerenes.. Chemical communications 2013, 49(80): 9092-9094

\section{ISSUE DATE:}

2013-10-14

URL:

http://hdl.handle.net/2433/192996

\section{RIGHT:}

(c) The Royal Society of Chemistry 2013; This is not the published version. Please cite only the published version.; この論文は出版社版で ありません。引用の際には出版社版をご確認ご利用ください。 


\title{
Electron-rich Carbon Nanorings as Macrocyclic Hosts for Fullerenes ${ }^{\dagger}$
}

\author{
Koji Miki,* Tsuyoshi Matsushita, Yuki Inoue, Yoshinori Senda, Toshiyuki Kowada and Kouichi Ohe* \\ Received (in $X X X, X X X)$ Xth $X X X X X X X X X 20 X X$, Accepted Xth $X X X X X X X X X 20 X X$ \\ DOI: 10.1039/b000000x
}

\section{${ }_{5}$ Electron-rich cycloparaphenyleneacetylenes as well as their twin "glasses-like" conjugates form stable complexes with fullerenes.}

Host molecules of fullerene have been intensively investigated in recent years for roles as separators of specific fullerenes as well as 10 building blocks of well-ordered fullerene-based nanostructures. ${ }^{1}$ After the discovery of the complexation of fullerenes with azacrown compounds ${ }^{2}$ and $\gamma$-cyclodextrin, ${ }^{3}$ a range of host molecules for constructing fullerene-containing electroactive nanomaterials has been developed. ${ }^{1 \mathrm{a}-\mathrm{d}}$ Because fullerene is a $\pi$ 15 conjugated spherical molecule, convex-concave $\pi$ - $\pi$ interactions between a fullerene and a $\pi$-conjugated tube-like structure have also been envisioned to form much more stable complexes. In fact, it was found that fullerenes can be included inside single-walled carbon nanotubes (SWNTs). ${ }^{4}$ After this intriguing study, two 20 examples of host-guest complexes of fullerene with carbon nanorings (CNRs), $\pi$-conjugated hydrocarbon macrocycles such as [6]cycloparaphenyleneacetylene $\quad([6] \mathrm{CPPA})^{5}$ and [10]cycloparaphenylene, ${ }^{6}$ were reported (Fig. 1). Most recently, the synthesis of SWNTs with perfectly defined diameters as well 25 as their fullerene-included peapods from [n]cycloparaphenylenes has aroused much interest. ${ }^{7-11}$ Although much attention has been paid to the properties of clusters consisting of multiple CNRfullerene complexes, there are no examples of complexes of fullerenes with two or more CNR conjugates. The inclusion 30 properties of [6]CPPA revealed both experimentally ${ }^{5,12}$ and theoretically ${ }^{13}$ prompted us to investigate a conjugate of two [6]CPPAs for inclusion of fullerenes.

Recently, we reported the efficient synthesis of strained pyridinecontaining macrocycles via a tin-mediated reductive aromatisation 35 reaction. ${ }^{14}$ A cross-coupling and reduction sequence for [6]CPPA precursors allowed us to find the [6]CPPAs formation via tinmediated reduction of 1,4-methoxycyclohexa-2,5-diene moieties (Scheme 1). Furthermore, this approach is applicable to synthesis of "glasses-like" twin CNRs, in which two [6]CPPA moieties are 40 covalently joined by a phenyl ring (Fig. 2). ${ }^{15}$ Here, we report the complexation of fullerenes with anthracene-containing [6]CPPAs and twin CNRs synthesised via the new synthetic approach.

The $\mathrm{D}_{3 \mathrm{~h}}$ symmetric CNR precursors 1 were synthesised from cis-9,10-diethynyl-9,10-dimethoxy-9,10-dihydroanthracene with 45 the corresponding $p$-diiodobenzene by means of palladium and copper catalysts (see the Electronic Supplementary Information (ESI)). ${ }^{16}$ Subsequently, the tin-mediated reductive aromatisation of CNR precursors 1 with one equivalent of fullerene was carried

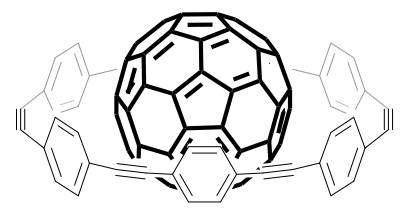

[6]CPPA $\supset \mathrm{C}_{60}$

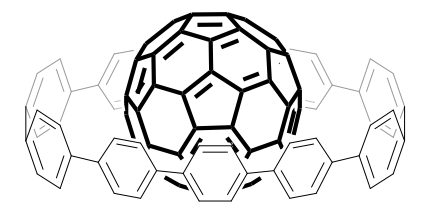

[10]CPP $\supset \mathrm{C}_{60}$
${ }_{50}$ Fig. 1 Reported 1:1 complexes of $\pi$-conjugated CNRs and fullerene.

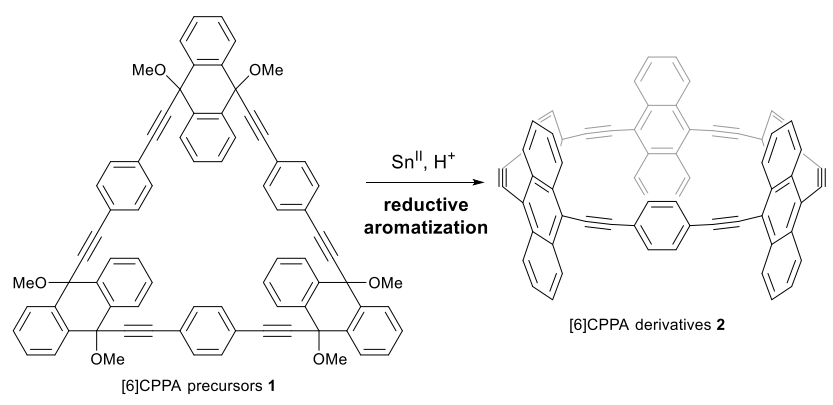

Scheme 1 Synthesis of anthracene-containing [6]CPPA by 55 reductive aromatisation.

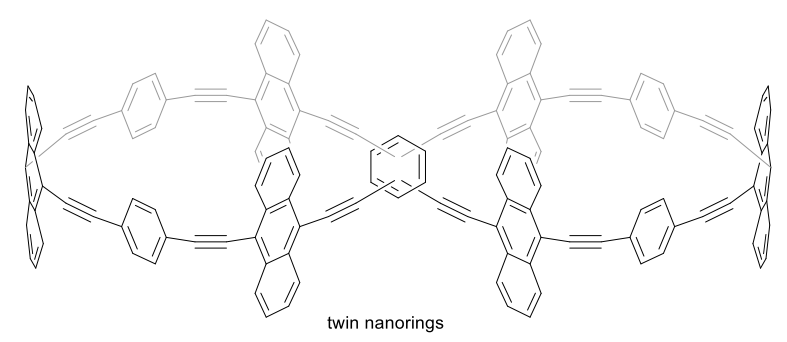

Fig. 2 Twin CNRs as hosts for fullerenes.

60 out (Scheme 2). After the reduction, the corresponding CNRfullerene complex $2 \supset \mathrm{C}_{60}$ was successfully isolated in $51 \%$ yield. ${ }^{17}$ The reductive aromatisation of $\mathbf{1}^{\prime}$ bearing electron-donating butoxy groups proceeded smoothly to afford the complex $\mathbf{2}^{\prime} \supset \mathrm{C}_{60}$ in $35 \%$ yield. The CNR-fullerene complexes $2 \supset \mathrm{C}_{60}$ and $\mathbf{2}^{\prime} \supset \mathrm{C}_{60}$ in the ${ }_{65}$ solid state are stable in the dark, but those in solution are not stable, especially under air. In the measurement of variable temperature (VT) ${ }^{1} \mathrm{H}$ NMR of $2 \supset \mathrm{C}_{60}\left(-90{ }^{\circ} \mathrm{C}\right.$ to $30{ }^{\circ} \mathrm{C}$ in $\left.\mathrm{CD}_{2} \mathrm{Cl}_{2}\right)$, no temperature-dependent signal separations were observed (concentration: $8.2 \times 10^{-4} \mathrm{~mol} \cdot \mathrm{dm}^{-3}$ ). ${ }^{18}$ Because no notable signals 70 of free host 2 were observed using ${ }^{1} \mathrm{H}$ NMR, even at low temperature, the association constant $\left(K_{\mathrm{a}}\right)$ of $2 \supset \mathrm{C}_{60}$ is estimated to be larger than $5 \times 10^{6} \mathrm{dm}^{3} \cdot \mathrm{mol}^{-1}$ by considering the concentration 


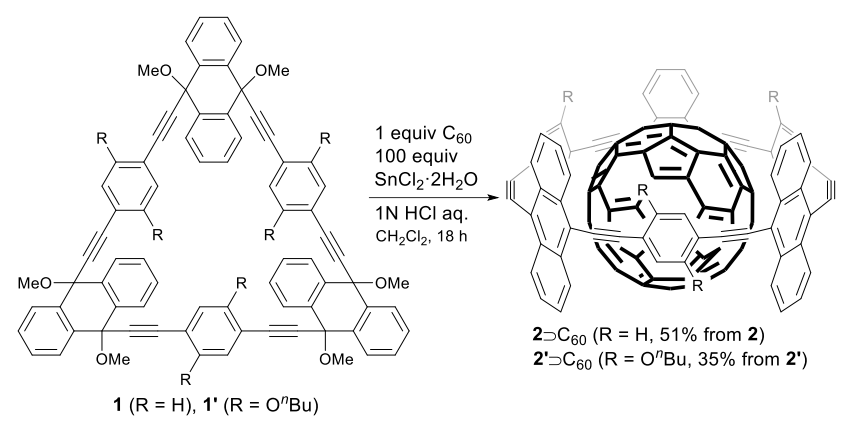

Scheme 2 Reductive aromatisation of CNR precursors 1 with fullerene.

5 of $2 \supset \mathrm{C}_{60}$ and the detection limit of the free host. ${ }^{19}$

Because we established the new synthetic route to obtain stable CNR-fullerene complexes, we focused our attention on twin CNRfullerene complexes generated from twin CNR precursors 3 (Fig. 3). Although the twin CNR precursor 3a was not obtained, the 10 double macrocyclization of $\mathbf{4}$ with diiodide $\mathbf{5 a}$ afforded twin CNR precursors $\mathbf{3 b}$ and $\mathbf{3 c}$ in $11 \%$ and $9 \%$ yields, respectively (Scheme 3). ${ }^{20}$ Instead, precursors $\mathbf{3 a}$ and $\mathbf{3} \mathbf{a}^{\prime}$ bearing butoxy groups were selectively prepared via a stepwise coupling reaction of $\mathbf{6}$ with $\mathbf{5 a}$ or $\mathbf{5} \mathbf{a}^{\prime}$ (Scheme 4). With CNR precursors $\mathbf{3 a}$ and $\mathbf{3} \mathbf{a}^{\prime}$ in hand, we 15 carried out the synthesis of a complex of twin CNRs with two fullerene molecules. Although twin macrocycles $\mathbf{3 b}$ and $\mathbf{3 c}$ did not afford 1:2 complexes with fullerene, ${ }^{21} \mathbf{3 a}$ and $\mathbf{3} \mathbf{a}^{\prime}$ underwent reductive aromatisation in the presence of excess amounts of fullerene to afford 1:2 complexes of twin CNRs 7 and 7' with 20 fullerene (Scheme 5). The complex $7 \supset 2 \mathrm{C}_{60}$ was detected by matrix assisted laser desorption/ionization-time of flight (MALDI-TOF) mass spectroscopy (Fig. S4 in the ESI), but unfortunately could not be isolated successfully. This might be caused by its low stability. When one fullerene molecule interacts 25 with one of two CNRs in 7, the electron density of another CNR is decreased by charge transfer interaction. Therefore, the second complexation of $1: 1$ complex $7 \supset \mathrm{C}_{60}$ with fullerene gave the unstable $1: 2$ complex $7 \supset 2 \mathrm{C}_{60}$, which in fact was detectable by mass spectroscopy just after the reduction but decomposed under 30 purification. Instead, a 1:2 complex $\mathbf{7}^{\prime} \supset 2 \mathrm{C}_{60}$ bearing butoxy substituents on the CNRs was isolated in $79 \%$ yield, and its isotropic patterns was confirmed by MALDI-TOF mass spectroscopy (Figs. S5 and S6 in the ESI). Furthermore, bis(ethoxycarbonyl)methanofullerene $\left(\mathbf{m} \mathbf{C}_{\mathbf{6 0}}\right)^{22}$ could be included 35 inside twin CNRs $\mathbf{7}^{\prime}$ to form the corresponding $\mathbf{7}^{\prime} \supset 2 \mathbf{m C}_{\mathbf{6 0}}$ (Figs. S7 and S8 in the ESI). ${ }^{23}$ These results suggest that the charge transfer interaction between electron-accepting fullerenes and twin CNRs 7' having electron-donating butoxy groups might stabilise the 1:2 complexation. Because no significant changes were 40 observed in VT ${ }^{1} \mathrm{H}$ NMR spectra of 7' $\supset 2 \mathrm{C}_{60}$, the inclusion of two fullerene molecules with two CNRs was considered to be strong (Fig. S9 in the ESI). It is important to note that the high electron density of $\mathbf{7}^{\prime}$ is essential in the formation of their stable 1:2 complexes with fullerene as well as $\mathbf{m C}_{\mathbf{6 0}}$ molecules.

45 We carried out cyclic voltammetry of twin CNR-fullerene complex $\mathbf{7} \supset 2 \mathrm{C}_{60}$ as well as CNR-fullerene complexes $\mathbf{2} \supset \mathrm{C}_{60}$ and $\mathbf{2}^{\prime} \supset \mathrm{C}_{60}$ with tetrabutylammonium hexafluorophosphate as the supporting electrolyte in $o$-dichlorobenzene (see the ESI). The cyclic voltammogram of $2 \supset \mathrm{C}_{60}$ exhibits a reversible one-electron

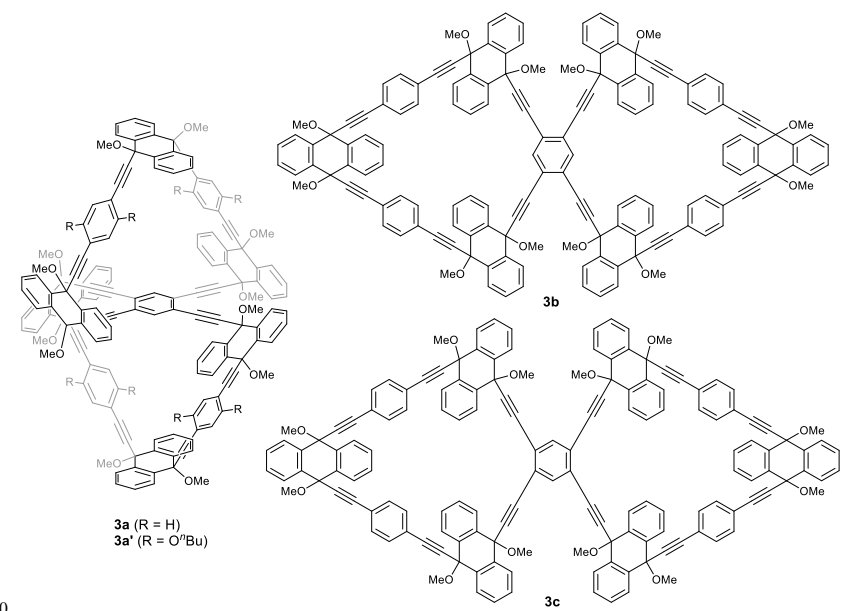

Fig. 3 Twin CNRs precursors 4.
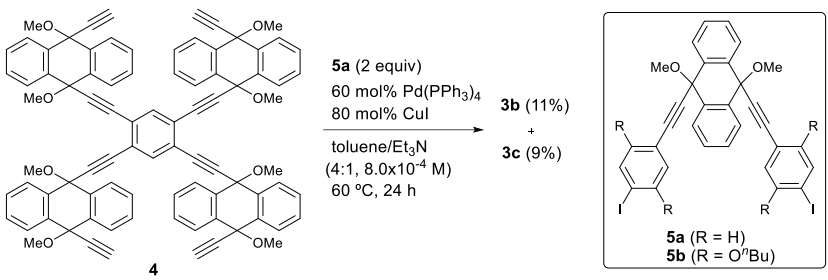

Scheme 2 Synthesis of twin CNRs precursors $\mathbf{3 b}$ and $\mathbf{3 c}$.

55

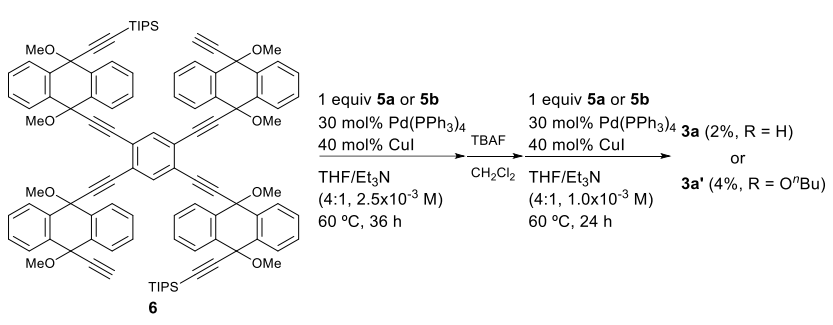

Scheme 3 Synthesis of twin CNRs precursors $\mathbf{3 a}$ and $\mathbf{3} \mathbf{a}^{\prime}$.

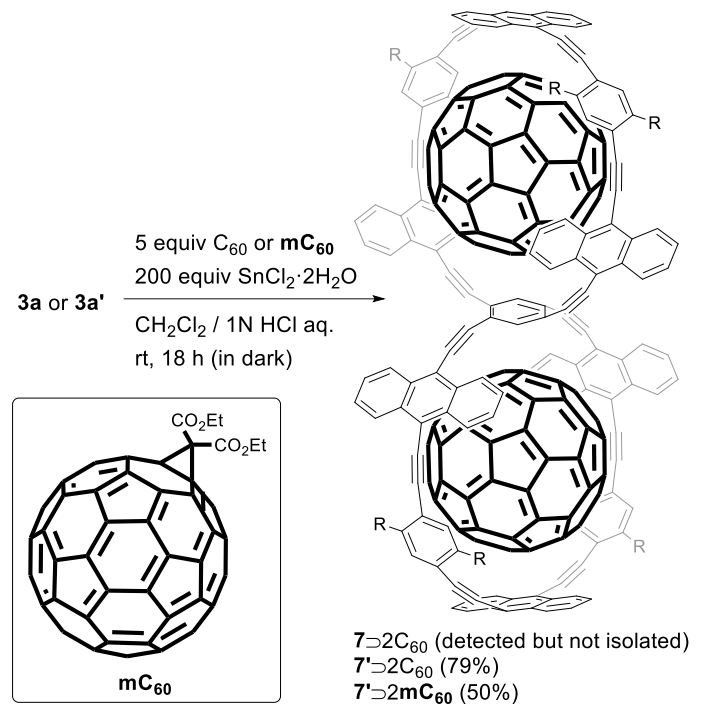

${ }_{60}$ Scheme 5 Synthesis of twin CNRs-fullerene complexes.

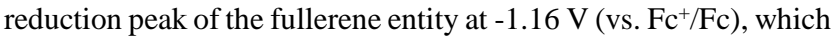
was cathodically shifted by $60 \mathrm{mV}$ as compared with that of pristine fullerene $(-1.10 \mathrm{~V})$. With $\mathbf{2}^{\prime} \supset \mathrm{C}_{60}$, the peaks retained their 
reversible shape and were shifted to a more negative potential ($1.29 \mathrm{~V}$ ). The first cathodic process corresponding to the reduction of the fullerene entity of $7{ }^{\prime} \supset 2 \mathrm{C}_{60}$ was observed at $-1.28 \mathrm{~V}$, which is similar to that of $\mathbf{2}^{\prime} \supset \mathrm{C}_{60}$. This difference in cathodic shifts of 5 the reduction potential between these complexes indicates that there is a stronger charge transfer interaction between a fullerene and butoxy-containing CNRs $\mathbf{2}^{\prime}$ and $\mathbf{7}^{\prime}$, and that the association constants of electron-rich $\mathbf{2}^{\prime}$ and $\mathbf{7}^{\prime}$ with fullerenes are larger than that of $2\left(K_{a} \gg>5 \times 10^{6} \mathrm{dm}^{3} \cdot \mathrm{mol}^{-1}\right) .{ }^{1 \mathrm{~d}, 24}$ Interestingly, no significant 10 decrement of reversible one-electron redox signals was observed in electrochemical reduction-oxidation cycles in either case. ${ }^{25}$ This indicates that the present CNR-fullerene complexes as well as reduced complexes are stable under the measurement conditions.

In summary, we have synthesised $\pi$-conjugated CNRs via a cross15 coupling and tin-mediated reductive aromatisation sequence. This methodology was applied to the synthesis of more complicated twin CNRs including two fullerene molecules. This is the first example of $1: 2$ complexation between a $\pi$-conjugated hydrocarbon macrocyclic system and two fullerene molecules. ${ }^{26} \mathrm{We}$ found that 20 the introduction of electron-donating groups on the CNRs significantly enhances the stability of the CNR-fullerene complexes by charge transfer interaction between the CNRs and fullerenes. The complexation of fullerenes with a range of CNR systems will find application in designing buckyball-nanotube 25 structures and investigating their unique function.

This work was supported by the Kurata Memorial Hitachi Science and Technology Foundation, a Grant-in-Aid for Scientific Research (C) and a Grant-in-Aid for Scientific Research on Innovative Areas from the Ministry of Education, Culture, Sports, ${ }_{30}$ Science, and Technology of Japan. We would like to thank Prof. Norihiro Tokitoh, Dr. Takahiro Sasamori and Dr. Tetsuaki Fujihara in Kyoto University for helpful discussions and supports of X-ray crystallographic analysis, and Dr. Keiko Kuwata in Kyoto University for measurements of MALDI-TOF mass spectrometry.

\section{${ }_{35}$ Notes and references}

${ }^{a}$ Department of Energy and Hydrocarbon Chemistry, Graduate School of Engineering, Kyoto University, Katsura, Nishikyo-ku, Kyoto 615-8510, Japan. Fax: +81-75-383-2495; Tel: +81-75-383-2499; E-mail: kojimiki@scl.kyoto-u.ac.jp; ohe@scl.kyoto-u.ac.jp

40 * Present Address: Immunology Frontier Research Center (IFReC),

Osaka University, 3-1 Yamadaoka, Suita, Osaka 565-0871, Japan.

$\dagger$ Electronic Supplementary Information (ESI) available: experimental details and characterisation data for all compounds. X-ray crystallographic data of $\mathbf{1}, \mathbf{3 b}$ and $\mathbf{3 c}$, cyclic voltammograms of $\mathbf{2} \supset \mathrm{C}_{60}, \mathbf{2}^{\prime} \supset \mathrm{C}_{60}$ and $\mathbf{7}^{\prime} \supset 2 \mathrm{C}_{60}$, 45 and NMR spectra of the new compounds. See DOI: 10.1039/b000000x/

1 (a) D. Canevet, E. M. Pérez, N. Martín, Angew. Chem. Int. Ed., 2011, 50, 9248; (b) E. M. Pérez, N. Martín, Pure Appl. Chem., 2010, 82, 523; (c) E. M. Pérez, N. Martín, Chem. Soc. Rev., 2008, 37, 1512; (d) K. Tashiro, T. Aida, Chem. Soc. Rev., 2007, 36, 189; (e) T. Nakanishi, 50 Chem. Commun., 2010, 46, 3425.

2 F. Diederich, J. Effing, U. Jonas, L. Jullien, T. Plesnivy, H. Ringsdorf, C. Thilgen, D. Weinstein, Angew. Chem., Int. Ed. Engl., 1992, 31, 1599.

3 T. Andersson, K. Nilsson, M. Sundahl, G. Westman, O. Wennerström,

55 Chem. Commun., 1992, 604. And see also: Z.-i. Yoshida, H. Takekuma, S.-i. Takekuma, Y. Matsubara, Angew. Chem. Int. Ed. Engl., 1994, 33, 1597.

4 B. W. Smith, M. Monthioux, D. E. Luzzi, Nature 1998, 396, 323.

5 T. Kawase, K. Tanaka, N. Fujiwara, H. R. Darabi, M. Oda, Angew. Chem. Int. Ed., 2003, 42, 1624.

6 (a) T. Iwamoto, Y. Watanabe, T. Sadahiro, T. Haino, S. Yamago, Angew. Chem. Int. Ed., 2011, 50, 8342; (b) J. Xia, J. W. Bacon, R. Jasti, Chem.
Sci., 2012, 3, 3018; (c) H. Isobe, S. Hitosugi, T. Yamasaki, R. Iizuka, Chem. Sci., 2013, 4, 1293.

657 (a) U. H. F. Bunz, S. Menning, N. Martín, Angew. Chem. Int. Ed., 2012, 51, 7094; (b) T. J. Sisto, R. Jasti, Synlett, 2012, 23, 483.

8 (a) E. S. Hirst, R. Jasti, J. Org. Chem., 2012, 77, 10473 and references cited therein; (b) R. Jasti, J. Bhattacharjee, J. B. Neaton, C. R. Bertozzi, J. Am. Chem. Soc., 2008, 130, 17646.

709 (a) K. Matsui, Y. Segawa, T. Namikawa, K. Kamada, K. Itami, Chem. Sci., 2013, 4, 84; (b) K. Itami, Pure Appl. Chem., 2012, 84, 907; (c) H. Omachi, Y. Segawa, K. Itami, Acc. Chem. Res., 2012, 45, 1378 and references cited therein; (d) H. Takaba, H. Omachi, Y. Yamamoto, J. Bouffard, K. Itami, Angew. Chem. Int. Ed., 2009, 48, 6112.

7510 (a) E. Kayahara, Y. Sakamoto, T. Suzuki, S. Yamago, Org. Lett., 2012, 14, 3284; (b) M. Fujitsuka, D. W. Cho, T. Iwamoto, S. Yamago, T. Majima, Phys. Chem. Chem. Phys., 2012, 14, 14585; (c) T. Iwamoto, Y. Watanabe, Y.-L. Sakamoto, T. Suzuki, S. Yamago, J. Am. Chem. Soc., 2011, 133, 8354; (d) S. Yamago, Y. Watanabe, T. Iwamoto, Angew. Chem. Int. Ed., 2010, 49, 757.

11 (a) S. Hitosugi, T. Yamasaki, H. Isobe, J. Am. Chem. Soc., 2012, 134, 12442; (b) S. Hitosugi, W. Nakanishi, H. Isobe, Chem. Asian J., 2012, 7, 1550; (c) S. Hitosugi, W. Nakanishi, T. Yamasaki, H. Isobe, Nature Commun., 2011, 2, 1505/1.

8512 (a) T. Kawase, Synlett, 2007, 2609. (b) T. Kawase, H. Kurata, Chem. Rev., 2006, 106, 5250 and references cited therein; (c) T. Kawase, Y. Nishiyama, T. Nakamura, T. Ebi, K. Matsumoto, H. Kurata, M. Oda, Angew. Chem. Int. Ed., 2007, 46, 1086. For related reviews, see: (d) M. Iyoda, J. Yamakawa, M. J. Rahman, Angew. Chem. Int. Ed., 2011, $90 \quad$ 50, 10522; (e) S. Toyota, Chem. Rev., 2010, 110, 5398; (f) K. Tahara, Y. Tobe, Chem. Rev., 2006, 106, 5274.

13 (a) Y. Zhao, D. G. Truhlar, J. Am. Chem. Soc., 2007, 129, 8440; (b) I. G. Cuesta, T. B. Pedersen, H. Koch, A. Sánchez de Merás, ChemPhysChem, 2006, 7, 2503.

9514 K. Miki, M. Fujita, Y. Inoue, Y. Senda, T. Kowada, K. Ohe, J. Org. Chem., 2010, 75, 3537.

15 Most recently, Jasti et al. reported the synthesis of cycloparaphenylene dimmers as a twin CNR system, see: J. Xia, M. R. Golder, M. E. Foster, B. M. Wong, R. Jasti, J. Am. Chem. Soc., 2012, 134, 19709.

10016 The structure of cyclotrimer $\mathbf{1}$ was confirmed by X-ray crystallographic analysis. See the SI.

17 CNR-fullerene complexes, $\mathbf{2} \supset \mathrm{C}_{60}$ and $\mathbf{2}^{\prime} \supset \mathrm{C}_{60}$, were detectable as 1:1 complexes in high resolution FAB mass spectrometry. See the SI.

18 In the case of $\mathbf{2}^{\prime} \supset \mathrm{C}_{60}$, the signals of the methylene protons on butoxy groups separated into two independent peaks below $-60{ }^{\circ} \mathrm{C}$. We suppose that this might be caused by the existence of two possible supramolecular isomers of $\mathbf{2}^{\prime} \supset \mathrm{C}_{60}$ related to the positions of butoxy groups. See the SI.

19 According to the instrument manual, the minimum sample 110 concentration of solute for ${ }^{1} \mathrm{H}$ NMR is usually $4 \times 10^{-4} \mathrm{~mol} \cdot \mathrm{dm}^{-3}$. Although the detection limit differs according to measuring object, we used this minimum concentration to estimate the equilibrium constant.

20 The structures of twin CNR precursors $\mathbf{3 b}$ and $\mathbf{3} \mathbf{c}$ were confirmed by X-ray crystallographic analyses. See the SI.

1521 After the reductive aromatisation of $\mathbf{3 b}$ with 2 equivalents of fullerene, the corresponding twin CNR and their 1:1 complex were detected by MALDI-TOF mass spectroscopy, but 1:2 complex was not observed at all (Figure S9 in the SI).

22 (a) C. Bingel, Chem. Ber., 1993, 126, 1957; (b) X. Camps, A. Hirsch, J. Chem. Soc., Perkin Trans 1, 1997, 1595.

23 By measuring ${ }^{1} \mathrm{H}$ NMR, we confirmed that $\mathbf{7}^{\prime}$ and $\mathbf{m C}_{60}$ form a $1: 2$ complex (Figure S10 in the SI).

24 (a) K. Tashiro, T. Aida, Chem. Soc. Rev., 2007, 36, 189. (b) H. Nobukuni, F. Tani, Y. Shimazaki, Y. Naruta, K. Ohkubo, T. Nakanishi,

125 T. Kojima, S. Fukuzumi, S. Seki, J. Phys. Chem. C, 2009, 113, 19694.

25 The irreversible second electron reduction peaks of $\mathbf{2} \supset \mathrm{C}_{60}, \mathbf{2}^{\prime} \supset \mathrm{C}_{60}$ and $7^{\prime} \supset 2 \mathrm{C}_{60}$ were observed around $-1.50 \mathrm{~V}$.

26 Recently, the 1:2 complexation of $\pi$-conjugated porphyrin-based macromolecules with fullerenes were reported, see: J. Song, N. Aratani, H. Shinokubo, A. Osuka, Chem. Sci., 2011, 2, 748 . 